\title{
European decision support modelling of long-term external doses received in inhabited areas contaminated by a nuclear power plant accident - 2: Post deposition contaminant mobility on outdoor surfaces
}

Hinrichsen, Yvonne; Andersson, Kasper Grann

Published in:

Journal of Environmental Radioactivity

Link to article, DOI:

10.1016/j.jenvrad.2019.04.009

Publication date:

2019

Document Version

Peer reviewed version

Link back to DTU Orbit

Citation (APA):

Hinrichsen, Y., \& Andersson, K. G. (2019). European decision support modelling of long-term external doses received in inhabited areas contaminated by a nuclear power plant accident - 2: Post deposition contaminant mobility on outdoor surfaces. Journal of Environmental Radioactivity, 204, 154-162.

https://doi.org/10.1016/j.jenvrad.2019.04.009

\section{General rights}

Copyright and moral rights for the publications made accessible in the public portal are retained by the authors and/or other copyright owners and it is a condition of accessing publications that users recognise and abide by the legal requirements associated with these rights.

- Users may download and print one copy of any publication from the public portal for the purpose of private study or research.

- You may not further distribute the material or use it for any profit-making activity or commercial gain

- You may freely distribute the URL identifying the publication in the public portal 


\title{
European decision support modelling of long-term external doses received in inhabited areas contaminated by a nuclear power plant accident -2 : post deposition contaminant mobility on outdoor surfaces
}

\author{
Yvonne Hinrichsen and Kasper G. Andersson* \\ Technical University of Denmark, Center for Nuclear Technologies, Frederiksborgvej 399, DK-4000 Roskilde, \\ Denmark
}

*Corresponding author: kgan@dtu.dk

Abstract: To enable estimation of time-integrated external doses to persons staying in an inhabited area radioactively contaminated by aerosols and gases released in connection with a large nuclear power plant accident, additional knowledge to that described in the first part of this paper is needed on the postdeposition migration of different types of contaminants on the various relevant types of environmental surface. This part of the paper describes how the migration processes are modelled dynamically in the European standard inhabited area dose model, ERMIN, and presents the newest parametric datasets. It is explained how the total information in both parts of the paper may be used to estimate doses received over time by populations in radioactively contaminated inhabited areas.

Keywords: external dose, nuclear power plant accident, radioactive, caesium, weathering, contamination

\section{Introduction}

According to a recent publication (Howard et al., 2017), the long term ingestion and external dose contributions received by inhabitants of areas contaminated by the Chernobyl accident was estimated to be about equal in magnitude, whereas the long term external dose contribution to the public in areas contaminated by the Fukushima accident has been estimated to be of the order of $80-90 \%$, and the corresponding ingestion dose only $10-20 \%$. In preparedness for possible future nuclear power plant accidents, it is thus highly important to be able to implement effective recovery strategies for contaminated inhabited areas. However, as per tradition, radioecology studies have over many decades to a very great extent focused on studies of mechanisms and parameters governing the post-deposition transfer of various radionuclides to man via foodchains. Therefore, these processes are today in general better understood than those determining external doses in inhabited areas. For example, the International Atomic Energy Agency has published a report of more than 600 pages on radionuclide transfer parameters for terrestrial and freshwater environments (IAEA, 2009), in which the terrestrial environments are all rural or natural (food producing).

Although a counterpart describing parameters and processes relevant to inhabited areas does not exist, there are of course also a range of publications that describe post-deposition transfer and natural removal of radiocontaminants deposited in inhabited areas. Many of these are based on studies of contamination from the Chernobyl accident. Unfortunately, time series measurements have not been made of the postdeposition migration of radioactive matter from the Fukushima accident on each of the various types of man-made surfaces representative of inhabited areas. Instead, the focus of the Japanese authorities has been on rapid carborne surveillance of dose rate in affected areas using KURAMA II detection systems 
(Kinase et al., 2015), which measure an uncollimated dose rate in a position close to the road surface. This provided valuable rough indications of the contamination pattern over large land areas. In relation to the actual average exposure of the local population, however, this measurement geometry would give an overrepresentation of the radiation from the nearby contaminated street surface. And since the natural decline in radioactivity on street surfaces has previously been found to be comparatively very rapid (Andersson, 2009), such repeated measurements would lead to overestimation of the rate at which the average dose rate declines in the area through natural processes. Qualitatively, however, these Japanese measurements illustrate that the decline in dose rate is as expected faster in urban areas, comprising surfaces with rapid natural weathering processes, than in rural areas, where the decline in dose rate level is largely dependent on the slow downward contaminant migration in soil (Kinase et al., 2015).

Identifying appropriate time functions representing the natural weathering and migration processes of contaminants on each type of surface is essential in enabling estimation of future time integrated doses and for instance residual doses received by people after treatment in a prescribed way of a given type of surface in the inhabited environment. The ERMIN dose model co-developed and coded at Public Health England (Charnock et al., 2009; Charnock, 2018; Andersson et al., 2008) that is used in the European decision support systems, RODOS (2018) and ARGOS (2018), to estimate external doses in inhabited areas, includes a system of formulae reflecting the post deposition mobility of radiocontaminants on the different types of outdoor surface (Jones et al., 2007). This paper describes the most recent methods and parameter sets that have been developed for implementation in ERMIN, e.g., considering contaminants with an expanded range of possible physicochemical forms compared to earlier versions, and including the latest available information. As in part 1 of the paper, the focus is on describing external dose contributions from contamination on outdoor surfaces. Other processes modelled in ERMIN that can contribute to dose in inhabited areas after airborne releases, such as contaminant deposition on indoor surfaces, contaminant deposition on humans, and inhalation of contaminants are outside the scope of this paper, and described elsewhere (e.g., Jones et al., 2007; Andersson et al., 2004; Byrne, 2009; Andersson et al., 2008). Also naturally occurring contaminant resuspension processes are omitted in this paper as they are generally not expected to lead to significant redistribution of contamination deposited on urban surfaces after a nuclear power plant accident (Ramzaev et al., 2006; Andersson et al., 2004). Forced dose reduction processes are in general not considered in the models in this paper, although they are an integral part of ERMIN.

\section{Materials and methods}

As described in part 1 of the paper, experience from Chernobyl and Fukushima has shown that a large nuclear power plant accident can lead to airborne releases of a wide range of radionuclides with different physicochemical forms (more or less reactive gases, aerosols of different sizes and with different features with respect to environmental mobility). For the purpose of modelling post-deposition migration processes it is important to distinguish between elemental iodine, which may deposit in large amounts, but will in general be rapidly removed by natural processes (precipitation) on impermeable surfaces (Roed, 1987), and deposited contaminant particles with different characteristics. Radioiodine dose rate contributions may be high in an early phase, but due to the short physical half-life of the most abundant iodine isotopes in a nuclear power reactor, radioiodine would not be likely to have important influence on 
external doses in later (recovery) time phases, particularly if other radionuclides than iodine and noble gases (notably caesium isotopes) are released.

If we, as argued in part 1 of the paper, concentrate on those particles that have a size that allows them to follow air streams over longer distances, these may be split into four different categories or model 'bins' (the general approach adopted in the ERMIN model). This includes a group of particles ranging in size between 0 and $2 \mu \mathrm{m}$, which is particularly representative of condensation mode contamination attached to ambient particles (Andersson, 2009). As mentioned in part 1 of the paper these typically had a radius of the order of half a micron in the Chernobyl and Fukushima cases. The contaminants associated with condensation mode particles are assumed to be rather readily soluble and would thus rapidly be in ionic form after deposition in the outdoor environment, as frequently reported after the Chernobyl accident (Andersson, 2009; Roed, 1987). Nevertheless, to illustrate the complexity of these issues, it should be mentioned that in an area very far from the release point from the Chernobyl accident, some low solubility caesium particles of this size range have been found, and increasing soil to milk contaminant transfer factors in that area over the first two years after the accident suggested that natural particle dissolution in the environment took considerable time (Hansen \& Hove, 1991). However, focusing on external dose, contaminants embedded in low solubility particles would in general be expected to be more rapidly weathered away from an impermeable surface than caesium on cationic form (Andersson, 2009). Therefore, modelling post-deposition mobility of such small low solubility particles in the same way as cationic caesium, which will be very strongly fixed in upper layers of many types of urban surface, may make the dose contribution estimates somewhat conservative.

Radiocaesium has a particularly great importance in modelling external doses after nuclear power plant accidents, as it will evaporate at comparatively low temperatures, and thus be likely to be released in great quantities from large accidents. At the same time, the decays of the key isotopes of concern in this context, ${ }^{134} \mathrm{Cs}$ and ${ }^{137} \mathrm{Cs}$, lead to emission of gamma photons with quite high energy and photon yield, particularly ${ }^{137} \mathrm{Cs}$ has a long physical half-life of ca. 30 years and the caesium cation has a rare marked tendency to be fixed in a range of minerals and also to be retained in the upper soil layers (Andersson, 2009). External dose rate contributions from caesium thus only slowly decline through natural processes, and would be of major concern in recovery (late phase) decisions for management of contaminated inhabited areas, as seen after both the Fukushima and Chernobyl accidents.

There is currently insufficient data available to enable specific detailed modelling of the retention of other radionuclides in ionic form on urban surfaces. However, high specific binding strength of caesium compared with any other potentially relevant ions has also been reported in laboratory studies of many urban construction materials (De Preter, 1990). Further, it has been demonstrated in field studies after the Chernobyl accident that the retention of cationic caesium in a variety of construction materials is considerably greater than that of, e.g., ruthenium (Roed, 1987), which was released in even greater quantity from the Chernobyl accident than was caesium (IAEA, 1991), but where the relevant isotopes, ${ }^{103} \mathrm{Ru}$ and ${ }^{106} \mathrm{Ru}$ are considerably more short-lived (physical half-lives of respectively $39.5 \mathrm{~d}$ and $1.0 \mathrm{y}$ ). Strontium deposited in water solution has for example been found to weather off a clay roof with a half-life of only ca. 2.5 months (Brown et al., 2016), whereas most of the caesium deposited in solution on a clay roof would remain over decades (Andersson, 2009). Thus modelling retention of all ionic contaminants 
using parameters derived for caesium would be expected to make the dose estimates somewhat conservative.

Larger low solubility particles will generally be expected to be removed from impermeable surfaces at a much faster rate than cationic caesium (Andersson, 2009). The main mechanisms driving the 'natural' removal of all contaminants are in general precipitation and anthopogenic impact such as traffic and routine cleaning (Wilkins, 1987; Andersson, 2009). Although time, rain intensity and rain frequency all have importance (Madoz-Escande et al., 2004; Madoz-Escande et al., 2005), data is currently not available to allow quantitative modelling according to these factors, and in any case, weather predictions over long time periods would be too uncertain to make use of such data. Therefore empirical formulae based on typical observations of the overall natural weathering process are used in the ERMIN model. The following sections report on the newest version of weathering parameter formulae and datasets, which have been derived for use in ERMIN. In the event of a new contaminating incident, case specific parameter studies should be made to continuously further improve and target model parameters. Also, an investigation of aerosol characteristics (including solubility) should be made so that the user could for the purpose of longterm dose prediction target the model assumptions for different aerosol groups to the specific case.

\section{Results}

\subsection{Contaminant mobility from paved areas}

For modelling the mobility of contaminants on paved areas, such as streets and walkways, the primary dataset of interest reflects the results of in situ measurements on such surfaces of radiocaesium in the town of Gävle, Sweden, which received one of the highest levels of contamination outside the former Soviet Union from the Chernobyl accident (Andersson, 2009). These measurements were made with collimated germanium detectors over a period stretching from the first week after the accident to more than ten years later (Karlberg, 1988; Andersson, 1991; Andersson et al., 2002).

The weathering process has generally been found to be rapid on such surfaces, although a bit of variation has been observed due to differences in traffic intensity, and also precipitation rates and routine street cleaning would play a role. Experiments have shown that there are no strong binding mechanisms of cationic caesium in asphalt bitumen (Andersson, 1991), as there are in for example soil or common roof tiles. It has also been demonstrated that the downward penetration of caesium into an asphalted road surface can over a 2-year weathering period be expected to be less than one millimetre (Andersson, 1991). Although the caesium may be selectively bound to street dust (De Preter, 1990), this does not slow down the removal rate, as the street dust is not strongly attached to the road surface (Andersson, 1991).

As there does not appear to be significant contaminant ion specific fixation mechanisms at play on these surfaces, the results recorded for cationic caesium should apply also to other contaminant ions. This agrees with the results of Warming $(1982 ; 1984)$ in a tracer experiment where ${ }^{86} \mathrm{Rb},{ }^{103} \mathrm{Ru}$ and ${ }^{140} \mathrm{Ba}$ were sprayed onto asphalt and concrete pavements in a solution, and a very large part of all tracers could be removed by simple firehosing some days later. 
The empirical weathering formula that was derived from the measurement time series recorded in Gävle was found to be generally consistent with information from in situ measurements over shorter periods of time of Chernobyl caesium weathering in Bavaria (Jacob et al., 1987). This formula is used for all contaminants deposited in more or less readily soluble form (Andersson et al., 2002):

$C(t)=C_{0} \cdot \exp \left(-\operatorname{Ln} 2 \cdot t / T_{Y_{2}}\right) \cdot\left(f_{1} \cdot \exp \left(-\operatorname{Ln} 2 \cdot t / T_{w 1}\right)+f_{2} \cdot \exp \left(-\operatorname{Ln} 2 \cdot t / T_{w_{2}}\right)\right)$,

where $C(t)$ is the contaminant concentration at time $t, C_{0}$ is the initial contaminant concentration after the deposition process, $T_{1 / 2}$ is the physical half-life of the radionuclide, $f_{1}$ is the fraction (on average ca. 0.7 on streets; estimated standard deviation 0.2 ) of the contamination removed with a short half-life of $\mathrm{T}_{\mathrm{w} 1}$ (ca. 120 days on streets; estimated standard deviation 40 days), and $f_{2}$ is the fraction ( $\left.1-f_{1}\right)$ of the contamination removed with a longer half-life of $\mathrm{T}_{\mathrm{w} 2}$ (on average ca. 3 years on streets; estimated standard deviation 1 year). The weathering process may take considerably longer, if there is very little human activity in the area, as recorded in areas deserted after the Chernobyl accident (Andersson, 2009).

The case is different if low solubility fuel particles are present. Sartor et al. (1974) found experimentally that removal of contaminants in particle form from impermeable road surfaces was largely independent of particle size, when the particles were larger than about $10 \mu \mathrm{m}$. Smaller particles are however increasingly difficult to remove, as they can enter cavities in structures, and be less prone to weathering. According to aerosol spectra recorded after the Chernobyl accident, ${ }^{140} \mathrm{La}$ and ${ }^{140} \mathrm{Ba}$ were representatives of the more refractory element radionuclides released (in fuel particles), having a contaminant AMAD (activity median aerodynamic diameter) of several microns (typically 2-5) even in the most remote areas to which dispersion was recorded (Rulik et al., 1989; Nair \& Darley, 1986). This indicates that fuel particles may be expected to be supermicroneous, in-line with findings from explosions impacting on materials that do not undergo phase transition during the explosion (Andersson et al., 2008a). This would also be expected to have been the case in Denmark, where ${ }^{140} \mathrm{La}$ and ${ }^{140} \mathrm{Ba}$ contaminants were recorded to have different characteristics with respect to surface weathering, than did for instance the radiocaesium isotopes that predominantly deposited in readily soluble submicron particle form. Over the first 22 days that followed the initial contamination deposition in Roskilde, Denmark, from the Chernobyl accident, some $22 \%$ of the lanthanum and barium was washed off concrete surfaces through natural processes (Roed, 1987, 1990). This corresponds to a weathering half-life of about 60 days. It is likely that routine street cleaning would speed up this process further, so that the value of $T_{w 3}$ in equation 2 below of 60 days (with an estimated standard deviation of 20 days) may be seen as a conservative estimate for dose estimation from particles in the 2-5 $\mu \mathrm{m}$ range.

$C(t)=C_{0} \cdot \exp \left(-\operatorname{Ln} 2 \cdot t / T_{1 / 2}\right) \cdot \exp \left(-\operatorname{Ln} 2 \cdot t / T_{w 3}\right)$

This formula can also be applied for larger fuel particle contaminants, although with a different value of $\mathrm{T}_{\text {w3 }}$. On the basis of experimental investigations of attachment of particles of different sizes to street surfaces (Sartor \& Gaboury, 1984; Sartor et al., 1974; Bender \& Terstriep, 1984; Owen et al., 1960; Terstriep et al., 1982), it would be expected that particles in the 5-10 $\mu \mathrm{m}$ range (and thus according to Sartor et al., 1974, also likely the particles in the 10-20 $\mu \mathrm{m}$ range) would have a half-life, $T_{w 3}$, of the order of 30 days (standard deviation estimated to 15 days). The environmental dissolution timespans in soils reported by Kashparov et al. (2004) are long compared with the time constants determining natural removal of deposited fuel particles, and may thus be ignored in this context. 
In general, ERMIN assumes that radioactive material weathered off from impermeable surfaces like walls, roofs and streets is led via drain systems to sewers, whereas any material weathered off from vegetation goes to the soil surface underneath.

\subsection{Contaminant mobility from roofs}

Measurement series performed in Denmark over a period of nearly 15 years after the Chernobyl accident of the level of radiocaesium contamination level on a range of common roof materials (concrete, slate, clay tile) showed that whereas the initial retention on the roof of contaminants after a wet deposition process varies considerably between roofing materials (see part 1 of this paper), the subsequent long-term weathering rates were after the Chernobyl accident found to vary rather little between the examined range of materials (Andersson, 2009). A shorter time-series of measurements made on German roofs (Roed \& Jacob, 1990) support the general validity of these findings, although only done for concrete and clay tile roofs. Common to these materials is that they generally contain minerals, which selectively and strongly fix and retain caesium cations (De Preter, 1990; Andersson, 1991). Other radionuclide ions would be expected to be less strongly held (Andersson, 2009; Brown, 2016), although it has been demonstrated that ruthenium in representative ionic forms is not very easily removed from a roof clay or concrete tile surface (Andersson, 1991). ERMIN uses weathering data based on the Chernobyl time series caesium measurements (Andersson, 2009) for all radionuclides in ionic form for these types of roof materials. This may lead to conservative estimates of long term doses for other radionuclides, which are in reality weathered off faster. However, the physical half-lives of other radionuclides that would on the basis of past experience be expected to be potentially released in relatively large amounts and could impinge on external dose (see part 1 of the paper) are considerably shorter than that of ${ }^{137} \mathrm{Cs}$, and caesium is among the more volatile elements with generally comparatively high release probability.

The empirical formula thus applied in ERMIN for all contaminant ions deposited in more or less readily soluble form on many types of roofs (clay, concrete, slate) is:

$C(t)=C_{0} \cdot \exp \left(-\operatorname{Ln} 2 \cdot t / T_{1 / 2}\right) \cdot\left(f_{1} \cdot \exp \left(-\operatorname{Ln} 2 \cdot t / T_{w 1}\right)+f_{2} \cdot \exp \left(-\operatorname{Ln} 2 \cdot t / T_{w 2}\right)\right)$,

where $C(t)$ is the contaminant concentration at time $t, C_{0}$ is the initial contaminant concentration after the deposition process, $T_{1 / 2}$ is the physical half-life of the radionuclide, $f_{1}$ is the fraction (on average ca. 0.5 on these roof types; estimated standard deviation 0.1 ) of the contamination removed with a short half-life of $T_{w 1}$ (ca. 730 days; estimated standard deviation 85 days), and $f_{2}$ is the fraction (1- $f_{1}$ ) of the contamination removed with a longer half-life of $\mathrm{T}_{\mathrm{w} 2}$ (on average ca. 35 years; estimated standard deviation 7 years). Also sandstone roof tiles contain intact micaceous substances (De Preter, 1990), and would be expected to retain caesium in the same way.

The exception regarding radionuclide ions concerns very smooth (non-porous) surfaces, where experimentation suggests that the weathering of cationic caesium (and very likely also other ions) on a glass roof would occur with a half-life of the order of 95 days (Brown et al., 2016), and investigations from 
the European ECP-4 project (Mamaev et al., 1993) suggest a similar value for smooth (uncorroded) metal roof covers.

Regarding low solubility particle contamination, these types of surfaces would not constitute an environment that could over a reasonable time (compared with weathering half-lives) lead to very much fuel particle dissolution (Kashparov et al., 2004). For the parameterisation time series data exists for Chernobyl lanthanum and barium, associated with 2-5 $\mu \mathrm{m}$ particles, as measured on roof pavings (concrete, slate, clay tile) in Denmark. These contaminants were found to be weathered off the surface much more rapidly than caesium (Roed, 1987). A reasonable weathering half-life, $T_{w 3}$, would on the basis of that data seem to be of the order of 100 days. A probably dose conservative estimate of the weathering half-life for 5-10 $\mu \mathrm{m}$ (and larger) particles would judging from the data for paved horizontal surfaces be expected to be of the order of 60 days.

The general formula for contaminants deposited in fuel particle form becomes:

$C(t)=C_{0} \cdot \exp \left(-\operatorname{Ln} 2 \cdot t / T_{1 / 2}\right) \cdot \exp \left(-\operatorname{Ln} 2 \cdot t / T_{w 3}\right)$

\subsection{Contaminant mobility from outer walls}

For weathering of contamination on outdoor walls, generally very sparse information is available, primarily from measurements over time in Gävle (Andersson et al., 2002). It is clear that the weathering function on walls is not subject to strong fixation mechanisms, as construction bricks used for building walls are typically fired at such high temperatures that no specific strong ionic fixation sites remain (Andersson, 2009), and no significant difference was recorded in Gävle between plastered walls and clay brick walls (Andersson et al., 2002). The slow removal is largely due to wind abrasion and any horizontal precipitation components. It cannot be ruled out that larger particles may be more prone to wind-driven abrasion than small ones, which might be more protected in material cavities of suitable sizes, but the required data is not available to allow distinguishing on this parameter. Again a dose conservative approach is used, assuming that the larger particle contamination is weathered off walls at the same rate as is small particle contamination.

The generally assumed formula for contaminants deposited walls is (Andersson et al., 2002):

$C(t)=C_{0} \cdot \exp \left(-\operatorname{Ln} 2 \cdot t / T_{1 / 2}\right) \cdot \exp \left(-\operatorname{Ln} 2 \cdot t / T_{w 1}\right)$,

where $C(t)$ is the contaminant concentration at time $t, C_{0}$ is the initial contaminant concentration after the deposition process, $T_{1 / 2}$ is the physical half-life of the radionuclide, and $T_{w 1}$ is the weathering half-life of ca. 7 years (estimated standard deviation 2 years).

\subsection{Contaminant mobility from grass and small plants}

A large number of workers have over the years estimated the weathering half-life of contaminants on grass and small plants from experimentation, as such data is needed in traditional radioecology studies. The 
majority of experiments were carried out prior to the Chernobyl accident, but also some later studies have been made (Martin, 1964; Cline et al., 1965; Milbourn \& Taylor, 1965; Heinemann \& Vogt, 1980; Kirchmann et al., 1966; Chadwick \& Chamberlain, 1970; Krieger \& Burmann, 1969; Aarkrog et al., 1988; BIOMOVS, 1991; Mück et al., 1994; Eriksson et al., 1998; IAEA, 2009). There is no clear trend from this data with respect to dependence on physicochemical characteristics, where these have been specified, and it is thus assumed in the modelling that all the contaminant material is washed off from vegetation at the same rate. Based on the above references, the default value in the ERMIN model of the natural weathering half-life of contaminants from grass is $T_{w}=16$ days (with a standard deviation of 7 days). This value is somewhat shorter than the value of 25 days that has been recommended by Müller \& Pröhl (1993) for the purpose of the ECOSYS ingestion dose model. However, the 25 days correspond to the results of a field study where the field was completely protected against rain (Krieger \& Burmann, 1969). It should be noted that in case of prolonged rain, the natural weathering half-life may be shortened considerably (Madoz-Escande et al., 2004; Madoz-Escande et al., 2005; Madoz-Escande \& Santucci, 2005). On small plants, a similar typical value of $T_{w}=12$ days (estimated standard deviation of 5 days) was derived from the same literature.

The formula applicable to describe the concentration of contaminants on these surfaces at any time $t$ is of the form

$C(t)=C_{0} \cdot \exp \left(-\operatorname{Ln} 2 \cdot t / T_{1 / 2}\right) \cdot \exp \left(-\operatorname{Ln} 2 \cdot t / T_{w}\right)$,

where $C(t)$ is the contaminant concentration at time $t, C_{0}$ is the initial contaminant concentration after the deposition process, $T_{1 / 2}$ is the physical half-life of the radionuclide, and $T_{w}$ is the weathering half-life.

\subsection{Contaminant mobility from trees and shrubs}

Nearly half of the contamination on trees or shrubs will according to literature generally be removed with a short half-life, of about 30 days with a standard deviation of about 2 weeks (Mamikhin \& Klyashtorin, 2000; Nygren et al., 1994; Roed, 1988). It would seem reasonable to assume that the mechanism largely responsible for this transfer is the first heavy rainshowers (Roed, 1988). A small part of the order of $4 \%$ (estimated standard deviation of $4 \%$ ) is assumed to remain on the tree/shrub largely until it is felled (Mamikhin \& Klyashtorin, 2000; Roed, 1988), and the rest is assumed to have a weathering half-life of some 1.7 years, with an estimated standard deviation of about 1 year (Mamikhin \& Klyashtorin, 2000; Linkov et al., 1997). There may possibly be some species of trees for which this is not quite true, but the data available is sparse. On top of this, for coniferous trees, the shedding of needles will occur continuously with a half-life that depends on the exact species and climate, but can be assumed to be of the order of 4 years, with a standard deviation of about 2 years (Horticulture Diagnostic Laboratory, 2018). For deciduous trees/shrubs (in leaf at deposition), it is assumed that they shed their leaves during the first autumn, where nearly all the contamination is on the leaves (Roed, 1988). The time may here be assumed to vary rather homogeneously within about 8 weeks of the autumn.

It should be noted that the above parameter values were based almost exclusively on data for deposited soluble radiocaesium aerosols, and only Roed (1988) reported directly applicable information for garden trees. The mechanisms and/or rates of loss may well be different in forests. However, the values for caesium fit reasonably with results obtained after artificial contamination of respectively pine and birch 
forest tree crowns with ${ }^{90} \mathrm{Sr}$ in soluble form (Alexakhin \& Naryshkin, 1977). It is assumed that all contaminants behave in this way on trees and shrubs. No data is available for large low solubility contaminant particles, but these would be assumed to be removed somewhat more easily from the trees by precipitation, as they are on for example street surfaces. Applying values for caesium in solution would thus make the tree/shrub dose contribution estimates somewhat conservative. The methodology is thus here largely unchanged since the first parameterisation of ERMIN, where less emphasis was placed on physicochemical forms of the contaminants (Jones, et al., 2007).

Small amounts of long-lived radionuclides in soil will be transferred from the soil to trees/shrubs by root uptake. This will correspond to only few percent of the material initially deposited directly on the tree (Linkov et al., 1997), and is not considered in ERMIN. Unlike forested areas, leaves/needles in urban areas are generally not left to form a litter layer after they are shed. Therefore urban tree/shrub soil uptake will be much less than that in forests. The focus in the context of urban external dose is on the initially potentially very high tree/shrub canopy contamination due to the very effective aerosol filter constituted by foliage if the tree/shrub was in leaf at deposition (Roed, 1990). Only trees in leaf during deposition are considered in ERMIN, as the contamination level will otherwise be much less significant.

The formula applied to describe the concentration of contaminants on these surfaces at any time $t$ is of the form (Jones et al., 2007):

$C(t)=C_{0} \cdot \exp \left(-\operatorname{Ln} 2 \cdot t / T_{1 / 2}\right) \cdot\left(f_{1} \cdot \exp \left(-\operatorname{Ln} 2 \cdot t / T_{w 1}\right)+f_{2} \cdot \exp \left(-\operatorname{Ln} 2 \cdot t / T_{w 2}\right)+f_{3}\right)$,

where $C(t)$ is the contaminant concentration at time $t, C_{0}$ is the initial contaminant concentration after the deposition process, $T_{1 / 2}$ is the physical half-life of the radionuclide, $f_{1}$ is the fraction (on average ca. 0.46 , standard deviation of ca. 0.07) of the contamination removed with a half-life of $T_{w 1}=c a .30$ days, $f_{2}$ is the fraction $\left(1-f_{1}-f_{3}\right.$ ) of the contamination removed with a half-life of $T_{w 2}$ (on average ca. 1.7 years (s.d. 0.5 years) for deciduous and ca. 1.2 years (s.d. 0.4 years) for coniferous trees/shrubs taking into account continuous needle shedding), $f_{3}$ is the fraction (0.04) of the contamination assumed to stay until the tree/shrub is removed, and $T_{w 1}$ and $T_{w 2}$ are the corresponding removal half-lives, as given above.

Deciduous foliage shedding in the first autumn after the deposition occurred is assumed to change $f_{1}$ and $f_{2}$ to 0 .

\subsection{Contaminant mobility in soils}

The concentration of contaminants in soil is described in ERMIN as a function of time and vertical soil depth by a convection-dispersion model (Andersson et al., 1998; Jones et al., 2007), in-line with methodology suggested by, e.g., Schuller et al. (1997) and Bunzl et al (2000):

$$
C(x, t)=C_{0} \exp \left(-\ln (2) t / T_{1 / 2}\right)\left(\frac{1}{\sqrt{\pi D_{s} t}} \exp \left(-\frac{\left(x-v_{s} t\right)^{2}}{4 D_{s} t}\right)-\frac{v_{s}}{2 D_{s}} \exp \left(\frac{v_{s}}{D_{s}} x\right) \operatorname{erfc}\left(\frac{x+v_{s} t}{2 \sqrt{D_{s}} t}\right)\right)
$$

Here $T_{y / 2}$ is again the physical half-life, whereas $D_{s}$ is the effective dispersion coefficient, and $v_{s}$ is the convective velocity, defined respectively as 


$$
D_{s}=\frac{D}{1+K_{d} \frac{\rho}{\varepsilon}} \quad \text { (9) } \quad \text { and } \quad v_{s}=\frac{v_{w}}{1+K_{d} \frac{\rho}{\varepsilon}}
$$

where $D$ is the dispersion coefficient, $v_{w}$ is the mean pore water velocity, $K_{d}$ is the distribution coefficient of the contaminant in the soil, $\rho$ is the bulk soil density, and $\varepsilon$ is the soil porosity.

Bossew and Kirchner (2004), and Kirchner et al. (2009) have made thorough reviews of $D_{s}$ and $v_{s}$ by soil type on the basis of numerous assessments over different parts of Europe. For radiocaesium from Chernobyl, the resultant values were found to be as shown in Table 1. These values are in agreement with those reported by Ivanov (2009).

Of course the downward migration of contaminants in fuel particles is governed by entirely different physicochemical processes. Ivanov (2009) recorded much lower effective diffusion coefficients for contaminants contained in dispersed fuel particles deposited on soil. For sandy, loamy and peaty soils, these were all found to be of the order of $0.015 \mathrm{~cm}^{2}$ per year. The dispersed fuel particles measured by Ivanov (2009) were found to range up to about $18 \mu \mathrm{m}$ in size, and the larger of these $(>4 \mu \mathrm{m})$ seem as might be expected to be somewhat better retained in very top layers of undisturbed soils. Based on these results, the downward migration of fuel particles is seen to be exceedingly slow, and it could only lead to limited conservatism in external dose estimates to assume that the particles remain in the very top of the soil until they dissolve over months or years.

However, once the radionuclides are released from the fuel particles, other relevant contaminants can generally be expected to migrate faster than caesium (Andersson, 2009) as reflected by the differences in Table 2 of soil $K_{d}$. The dissolution of fuel particles in soil has in the Chernobyl case been reported by Kashparov et al. (2004) to take place according to the formulae below, which will be included in ERMIN:

If the material was initially oxidised, the dissolution rate constant after deposition in soil will be:

$\mathrm{k}\left(\right.$ years $\left.^{-1}\right)=0.6 * 10^{\left(-0.15^{*} \mathrm{pH}\right)}$ at $\mathrm{pH}<7.0$, and $\mathrm{k}=0.05$ at $\mathrm{pH}>7.0$

If the material was NOT initially oxidised, the dissolution rate constant after deposition in soil will be:

$\mathrm{k}\left(\right.$ years $\left.^{-1}\right)=40 * 10^{\left(-0.45^{*} \mathrm{pH}\right)}$ at $\mathrm{pH}<6.5$, and $\mathrm{k}=0.05$ at $\mathrm{pH}>6.5$

The $\mathrm{pH}$ values to be used in Kasparov et al.'s formulae would be based on easily made actual measurements in case of an accident, but may be assumed to mostly be in the range of 5.0-6.5 for mineral soils and 6.5-8.0 for more organic soils.

Theoretically, there should be some dependence of particle dissolution rates on particle sizes (Mercer, 1967). However, such data are not apparent from the data published by Kashparov et al. (2004). 
Table 1. Results of a review of values of $D_{s}$ and $v_{s}$ by soil type in different types of soil, based on Chernobyl (cationic) caesium assessment (Bossew and Kirchner, 2004; Kirchner et al., 2009).

\begin{tabular}{|c|c|c|c|c|c|c|}
\hline Soil group & GM & GSD & AM & SD & Min & Max \\
\hline \multicolumn{7}{|c|}{ Parameter: $D_{\mathrm{s}}\left(\mathrm{cm}^{2}\right.$ per year $)$} \\
\hline All soils & 0.22 & 3.1 & 0.37 & 0.4 & 0.02 & 1.9 \\
\hline Clay/Loam & 0.20 & 4.6 & 0.36 & 0.3 & 0.02 & 0.8 \\
\hline Sand & 0.11 & 2.3 & 0.16 & 0.2 & 0.03 & 0.6 \\
\hline Organic & 0.94 & 1.8 & 1.07 & 0.7 & 0.63 & 1.9 \\
\hline Unspecified & 0.27 & 2.6 & 0.37 & 0.3 & 0.04 & 0.8 \\
\hline \multicolumn{7}{|c|}{ Parameter: $\mathrm{v}_{\mathrm{s}}(\mathrm{cm}$ per year) } \\
\hline All soils & 0.18 & 3.3 & 0.27 & 0.2 & 0.00 & 0.9 \\
\hline Clay/Loam & 0.06 & 17.5 & 0.24 & 0.3 & 0.00 & 0.6 \\
\hline Sand & 0.15 & 1.7 & 0.17 & 0.1 & 0.07 & 0.6 \\
\hline Organic & 0.69 & 1.6 & 0.73 & 0.3 & 0.40 & 0.9 \\
\hline Unspecified & 0.22 & 1.6 & 0.24 & 0.1 & 0.09 & 0.5 \\
\hline
\end{tabular}

GM: geometric mean; GSD: geometric standard deviation; AM: arithmetic mean; SD: arithmetic standard deviation.

It may be noted that values for the groups 'all soils' and 'unspecified soil type' are generally in reasonable agreement, as they would be if the unspecified category in reality spans representatively over different soil types. Also values reported for weapons fallout have been reported by Kirchner (2009), and these are in most cases comparable with those for Chernobyl data. A lognormal distribution (using the geometric mean) is assumed (as favoured by Kirchner et al., 2009) in the uncertainty evaluation feature that is prepared for ERMIN. Minimum and maximum values are used as boundaries.

Values of $D_{s}$ and $v_{s}$ for other radioelements than caesium can be found by multiplying the values in Table 1 for caesium by the 'retardation factor' relationship $\left(\mathrm{R}=1+K_{d} \frac{\rho}{\varepsilon}\right)$ (Kirchner et al., 2009) (i.e. by the 'retardation factor' for the new element divided by that for caesium), applying appropriate values for all parameters (see above) for the soil type and element in question.

For the $K_{d}$ values in equations 9 and 10, a wide range of data is available (also by soil type) from a relatively recent review by IAEA (2009). Table 2 shows the values for the 3 radioelements that would be thought to be of primary importance for external dose, but data for other elements of any potential significance (Am, $\mathrm{Ba}, \mathrm{Ce}, \mathrm{Cm}$, La, Mo, Nb, Np, Pu, Rb, Sb, Sr, Te, $\mathrm{U}$ and $\mathrm{Zr}$ ) are also available for use in the specified format from the report from IAEA (2009), although generally based on much fewer data and often without soil type specific data or standard deviations. All values of $K_{d}$ are assumed to be lognormally distributed based on the Central Limit Theorem, and the assumption of lognormal is generally supported by empirical evidence (Sheppard et al., 2009).

As for bulk soil density, this normally varies within a short range of $1.4-1.7 \mathrm{~g} / \mathrm{cm}^{3}$ for sandy soil, whereas it is typically 1.1-1.4 g/ $\mathrm{cm}^{3}$ for clay/loam soil (Brewer, 1964; Chesworth, 2008). An assumption of uniform distribution seems reasonable over these rather small intervals. The relationship between bulk soil density and porosity is given by: 
(Blake \& Hartge, 1986; Brady \& Weil, 1996). In most soils the particle density can be assumed to be around $2.65 \mathrm{~g} / \mathrm{cm}^{3}$ (Brady \& Weil, 1996). This is the density of quartz, which is the dominant mineral in most soils.

For organic soils, the porosity has on the basis of 180 soil samples been shown to have the following dependence on soil organic carbon (SOC) (Franzluebbers, 2011):

Soil porosity $\left(\mathrm{m}^{3} / \mathrm{m}^{3}\right)=-0.20+0.89(1-\exp (-0.067 \cdot \mathrm{SOC}[\mathrm{g} / \mathrm{kg}]))$,

whereas the bulk soil density depends on the soil organic C in the following way (Hossain et al., 2015):

Bulk soil density $\left(\mathrm{g} / \mathrm{cm}^{3}\right)=1.56 \exp (-0.0063 \cdot \mathrm{SOC}[\mathrm{g} / \mathrm{kg}])$.

By including these formulas in ERMIN the user can specify the values for organic soils directly from the soil organic $\mathrm{C}$ content, which is easily measurable by ignition (remembering the rule of thumb - the van Bemmelen factor - that organic matter generally contains about 58 percent organic carbon (Périé \& Ouimet, 2008)).

Table 2 Results of a review of values of $K_{d}$ for 3 important elements by soil type in different types of soil, based on hundreds (for $\mathrm{Cs}$ and $\mathrm{I}$ ) of field assessments (in units of $\mathrm{L} / \mathrm{kg}=\mathrm{cm}^{3} / \mathrm{g}$ ).

\begin{tabular}{|c|c|c|c|c|c|c|}
\hline Soil group & GM & GSD & AM & SD & Min & Max \\
\hline \multicolumn{7}{|c|}{ Contaminant: Cs } \\
\hline All soils & $1.2 \mathrm{E} 3$ & 7 & $6.1 \mathrm{E3}$ & $2.1 \mathrm{E} 4$ & 4.3 & $3.8 \mathrm{E} 5$ \\
\hline Clay/Loam & $5.5 \mathrm{E} 3$ & 4 & $2.2 \mathrm{E} 4$ & $6.7 \mathrm{E} 4$ & $5.7 \mathrm{E} 2$ & $3.8 \mathrm{E} 5$ \\
\hline Sand & $5.3 \mathrm{E} 2$ & 6 & $2.2 \mathrm{E} 3$ & $5.0 \mathrm{E} 3$ & $1.0 \mathrm{E} 1$ & $3.5 \mathrm{E} 4$ \\
\hline Organic & $2.7 \mathrm{E} 2$ & 7 & $3.0 \mathrm{E} 3$ & $1.2 \mathrm{E} 4$ & 4.3 & $9.5 \mathrm{E} 4$ \\
\hline Unspecified & $1.7 \mathrm{E} 3$ & 5 & $6.7 \mathrm{E3}$ & $1.5 \mathrm{E} 4$ & $4.0 \mathrm{E} 1$ & 5.5E4 \\
\hline \multicolumn{7}{|c|}{ Contaminant: I } \\
\hline All soils & 5.4 & 6 & $2.5 \mathrm{E} 1$ & 7.0E1 & $1.0 \mathrm{E}-2$ & $5.8 \mathrm{E} 2$ \\
\hline Clay/Loam & 6.8 & 6 & $2.1 \mathrm{E} 1$ & $3.0 \mathrm{E} 1$ & 1.0 & $1.2 \mathrm{E} 2$ \\
\hline Sand & 3.6 & 8 & 1.3E1 & 2.0E1 & $1.0 \mathrm{E}-2$ & $1.3 \mathrm{E} 2$ \\
\hline Organic & $3.6 \mathrm{E} 1$ & 4 & $9.3 \mathrm{E} 1$ & $1.8 \mathrm{E} 2$ & 8.5 & $5.8 \mathrm{E} 2$ \\
\hline Unspecified & 2.6 & 6 & $2.0 \mathrm{E} 1$ & 7.0E1 & $1.0 \mathrm{E}-1$ & $3.7 \mathrm{E} 2$ \\
\hline \multicolumn{7}{|c|}{ Contaminant: Ru } \\
\hline All soils & $2.7 \mathrm{E} 2$ & 8 & 4.7E3 & 1.7E4 & 5.0 & $6.6 \mathrm{E} 4$ \\
\hline Clay/Loam & $5.0 \mathrm{E} 2$ & 2 & $6.0 \mathrm{E} 2$ & 3.6E2 & $2.0 \mathrm{E} 2$ & 9.9E2 \\
\hline Sand & $3.6 \mathrm{E} 1$ & 6 & 7.7E1 & 9.0E1 & 5.0 & $6.6 \mathrm{E} 4$ \\
\hline Organic & - & - & $6.6 \mathrm{E} 4$ & - & - & - \\
\hline Unspecified & $1.4 \mathrm{E} 2$ & 3 & $2.3 \mathrm{E} 2$ & $2.1 \mathrm{E} 2$ & $3.4 \mathrm{E} 1$ & $4.9 \mathrm{E} 2$ \\
\hline
\end{tabular}

GM: geometric mean; GSD: geometric standard deviation; AM: arithmetic mean; SD: arithmetic standard deviation.

\subsection{Combining the information for external dose prediction}

This section gives a short description of how the information in both parts of this paper may be applied in prognoses of how the dose rate will vary with time after a contaminating event. For simplicity assume that 
a dry deposition of only ${ }^{137} \mathrm{Cs}$ (relevant emitted gamma energy: $0.662 \mathrm{MeV}$ ) has taken place to an area that may be adequately described by the type of semi-detached house environment described in part 1 of the paper (dose factors for a range of other types of environments exist in ERMIN (Jones et al., 2007), and the list of available data that may be used was recently expanded (Hinrichsen \& Andersson, 2018). The following describes in crude terms the way ERMIN operates.

The initial contamination level on the short-cut grassed reference surface is assumed to have been measured (or if measurements are not available, estimated using a dispersion/deposition model in the decision support system). This contamination level (unit: $\mathrm{Bq} \mathrm{mm}^{-2}$ on the reference surface) is multiplied by the set of factors for relative deposition on different surfaces for dry deposition from Table 1 of part 1 of the paper (for the relevant measured or assumed physicochemical form). This gives the initial contamination level on each type of surface in the environment (unit: $\mathrm{Bq} \mathrm{mm}^{-2}$ ).

For each type of contaminated surface, Table 6 in part 1 of the paper gives the normalised contribution to kerma (unit: pGy per $y \mathrm{~mm}^{-2}$ on the relevant surface type) in a detection point, where people may be staying (e.g., on the ground floor or first floor). By multiplying these kerma values by the gamma yield constant (unit: $\gamma \mathrm{s}^{-1}$ per $\mathrm{Bq}$ ) for the radionuclide in question ( 0.85 for ${ }^{137} \mathrm{Cs}$ daughter nuclide ${ }^{137 \mathrm{~m}} \mathrm{Ba}$ ) a kerma rate contribution (unit: $\mathrm{pGy} \mathrm{s}^{-1}$ per Bq mm $\mathrm{m}^{-2}$ ) is obtained. This kerma rate contribution can be multiplied by the initial contamination level on the given surface to obtain the initial contribution of the type of surface to kerma rate in the given position (unit: $\mathrm{pGy} \mathrm{s}{ }^{-1}$ ). By multiplying this by the time function given in this paper for the relevant surface type and physicochemical form, the kerma rate contribution of the type of surface at any point in time can be estimated. Conversion factors from air kerma to effective dose are given by ICRP (1997) and are for most relevant energies of the order of unity.

As an example, Figure 1 shows the decline with time of kerma contributions (essentially kerma rate contributions) per unit initial level of contamination on each type of surface in the semi-detached house environment. The detection area is here indoors on the ground floor. Note that the figures here only show the natural decline due to contaminant mobility and do not include the decay due to the physical half-life (for ${ }^{137} \mathrm{Cs}$ : ca. 30 years). It is seen that due to the different initial deposition and environmental mobility of contaminants with different physicochemical forms on different surfaces, some kerma rate contributions comparatively quickly become unimportant, whereas other remain high over very long periods. It should be noted that in this example, all ground areas have been assumed to be grassed. The comparatively rapid natural removal of large low solubility contaminant particles on impermeable surfaces is also visible in Figure 1. 

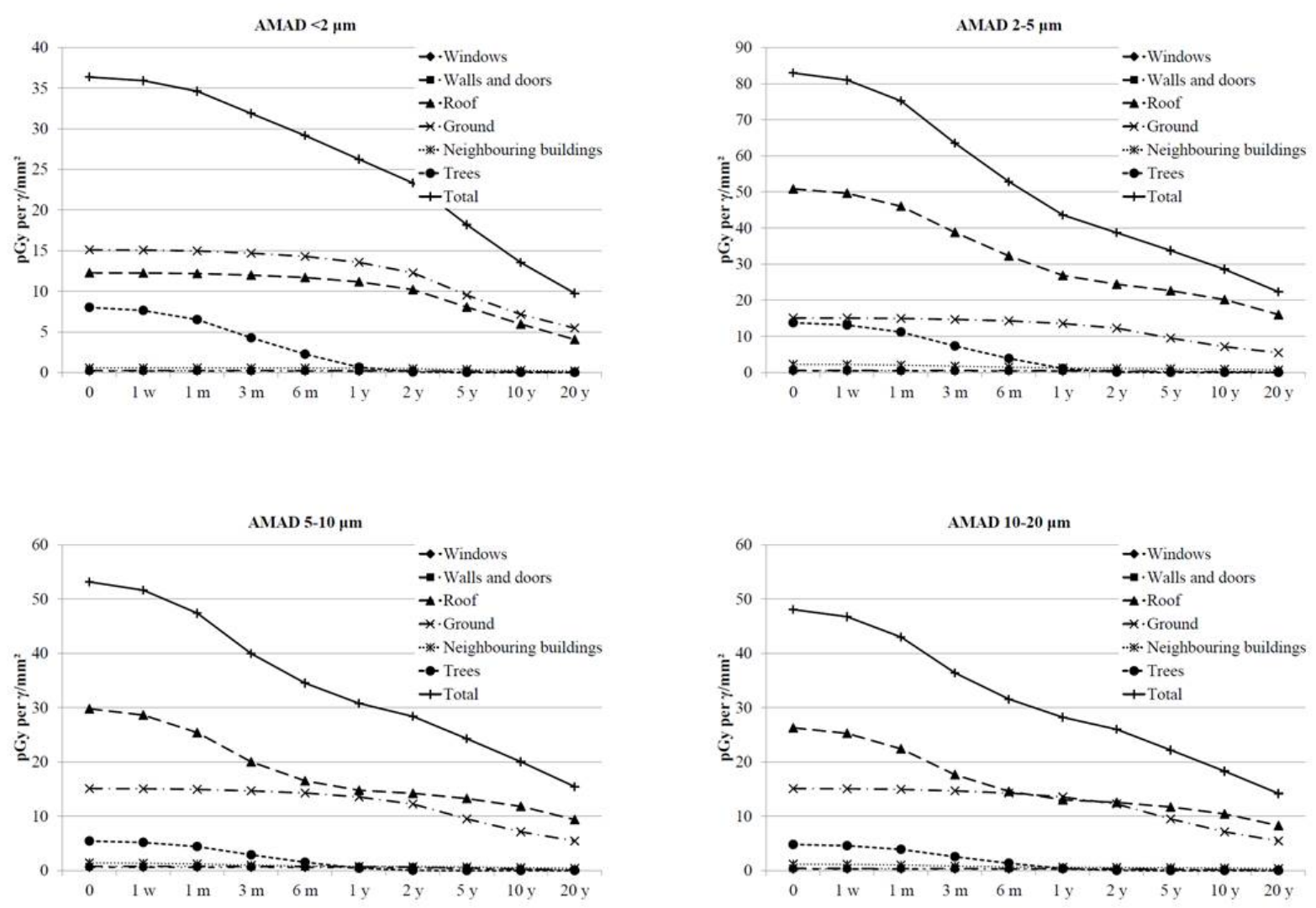

Figure 1. Natural decline with time in kerma contributions from different contaminated surface types per gamma initially emitted from the contamination on that surface per unit area. The detection point is here located on the ground floor of the building and all ground areas are assumed to be grassed. The physical half-life of ${ }^{137} \mathrm{Cs}$ is here not included in the calculations.

As can be seen, which of the contaminated surfaces contribute most to the kerma depends on the physicochemical form. Figure 2 shows the results of similar calculations, but here all ground areas were assumed to be paved.In comparison to the grassed ground areas, the deposition velocity is considerably lower (as seen in the tables of part I of the paper), and the decline in the ground kerma rate contribution is comparatively faster (Andersson et al., 2009). 

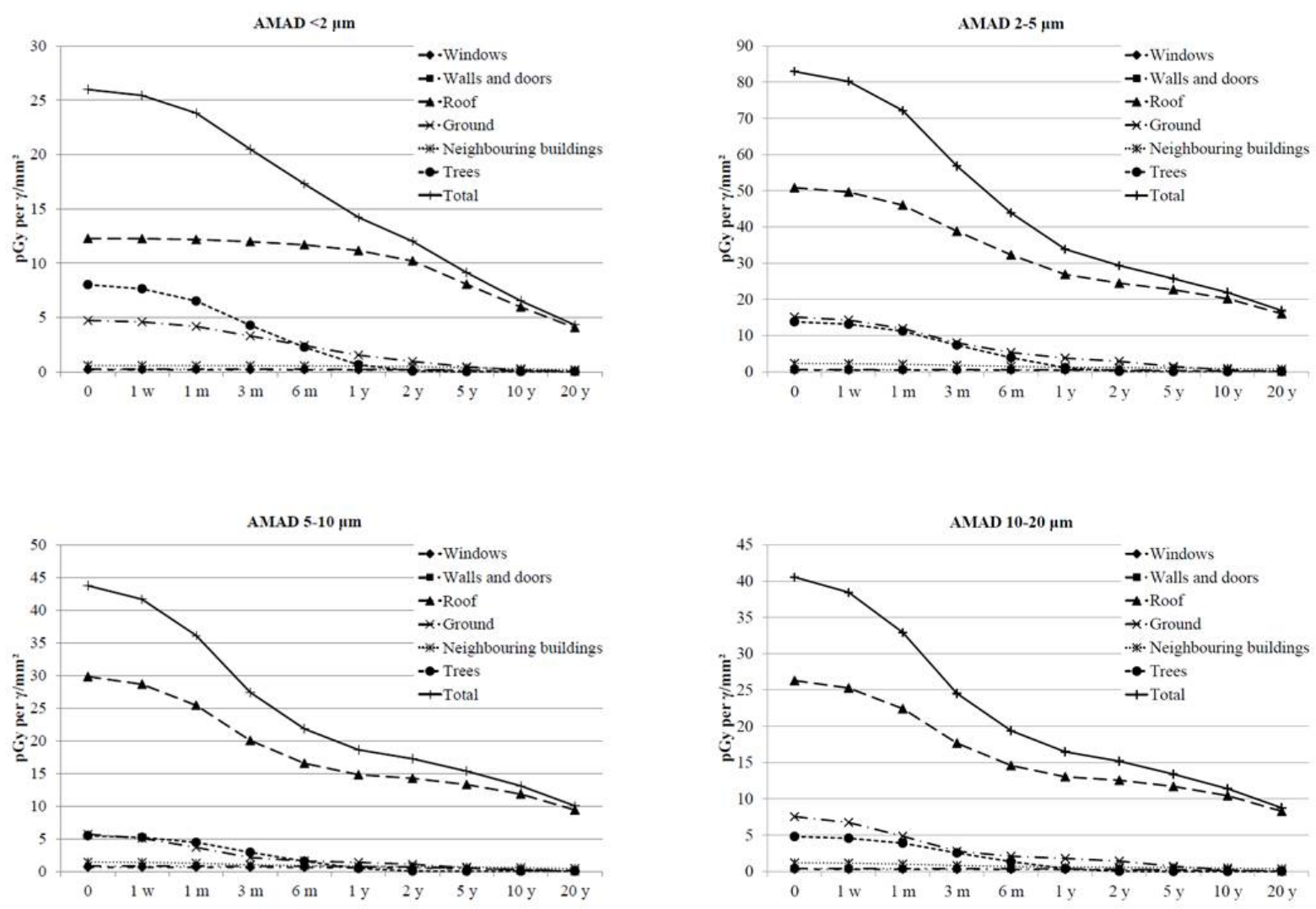

Figure 2. Natural decline with time in kerma contributions from different contaminated surface types per gamma initially emitted from the contamination on that surface per unit area. The detection point is here located on the ground floor of the building and all ground areas are assumed to be paved. The physical half-life of ${ }^{137} \mathrm{Cs}$ is here not included in the calculations.

It should be noted that due to the high shielding effect of this type of brick building towards radiation coming from the outdoor environment, the kerma rate is for $0.662 \mathrm{MeV}$ radiation from the ground areas reported by Meckbach et al. (1987) to be of the order of ten times higher outdoors than indoors in this type of building. Of course the dose contributions calculated on the basis of this type of information are for specific locations indoors and outdoors and must be weighted by the fractions of time spent by people on different floors and outdoors in the different representative positions. An average figure for European urban populations of the percentage of time spent indoors is $87 \%$, with a $95^{\text {th }}$ percentile of $75 \%$ (Andersson, 2013). If the contaminated environment contains large grassed areas or areas of soil, it has been demonstrated that these will often contribute most to doses integrated over years (Andersson et al., 2009).

The importance of parameter uncertainties for important ERMIN calculation endpoints is currently being studied through calculations made at Public Health England in the European CONFIDENCE project. 


\section{Conclusion}

Whereas part 1 of this paper described the relative deposition on a range of different surfaces in the inhabited environment of a wide range of contaminants with different physicochemical characteristics, as well as resultant initial kerma rates in air in the environment, this second part is aimed at providing an overview of the approaches behind modelling the system of processes that determine the fate over time of radioactive substances after deposition.

Formulae are given for the decline in contamination level on different surfaces in the inhabited environment, under different conditions. The most recent parameter datasets derived for use in the European inhabited area decision support model, ERMIN, are reported, including estimates of uncertainties, which are often rather rough, due to the scarcity of available relevant data. Recently, refinements to the modelling have also been made to reduce overall uncertainties by better distinguishing between for instance construction material types, and soil type categories. Also, data libraries have been created for ERMIN with values reflecting the latest state of knowledge. A few calculation examples are given, to illustrate that the post-deposition migration, and thereby doses to affected persons, may greatly depend on contaminant characteristics and assumptions regarding the surface characteristics.

Brief information is given on how to apply the information from the two parts of the paper in estimating doses.

\section{Acknowledgments}

The authors would like to thank Dr. Thomas W. Charnock at Public Health England for valuable advice in drafting the paper.

Part of the research leading to these results was carried out in the CONFIDENCE project, which is part of the CONCERT project. This project has received funding from the Euratom research and training programme 20142018 under grant agreement No 662287.

An other part of the research leading to these results has received funding from the European Atomic Energy Community Seventh Framework Programme FP7/2012-2013 under grant agreement 323287.

\section{Disclaimer}

This publication reflects only the author's view. Responsibility for the information and views expressed therein lies entirely with the authors. The European Commission is not responsible for any use that may be made of the information it contains. 


\section{References}

Aarkrog, A., Bøtter-Jensen, L., Chen, Q.J., Dahlgaard, H., Hansen, H., Holm, E., Lauridsen, B., Nielsen, S.P. \& Søgaard-Hansen, J., 1988. Environmental Radioactivity in Denmark in 1986, Riso Report R-549, ISBN 87550-1339-2

Alexakhin R. M. \& Naryshkin, M.A., 1977. Migration of radionuclides in forest biogeocenoses, Science, p. 144

Andersson, K.G., 1991. Contamination and decontamination of urban areas, Ph.D. Thesis, Ris $\emptyset$ National Laboratory.

Andersson, K.G., 2009. Migration of radionuclides on outdoor surfaces, Chapter 5 (pp. 107-146) in K.G. Andersson (editor): Airborne radioactive contamination in inhabited areas, Book Series Radioactivity in the Environment vol. 15 (series editor: M.S. Baxter), Elsevier, ISBN 978-0-08-044989-0, ISSN 1569-4860.

Andersson, K.G., 2013. On the current needs in European decision support tools for contaminated areas, Radioprotection Vol. 48, No. 5, pp. 57-64, ISSN 0033-8451.

Andersson, K.G., Brown, J., Mortimer, K., Jones, J.A., Charnock, T., Thykier-Nielsen, S., Kaiser, J.C., Proehl, G. \& Nielsen, S.P., 2008. New developments to support decision-making in contaminated inhabited areas following incidents involving a release of radioactivity to the environment, J. Environmental Radioactivity, vol. 99, pp. 439-454.

Andersson, K.G., Roed, J. \& Fogh, C.L., 2002. Weathering of radiocaesium contamination on urban streets, walls and roofs, J. Environmental Radioactivity vol. 62, no.1, pp. 49-60.

Andersson, K.G., Roed, J., Byrne, M.A., Hession, H., Clark, P., Elahi, E., Byskov, A., Hou, X.L., Prip, H., Olsen, S.K. \& Roed, T., 2004. Airborne contamination in the indoor environment and its implications for dose, Risoe-R-1462(EN), Risoe National Laboratory, Roskilde, Denmark, ISBN 87-550-3317-2, 100 p.

Andersson, K.G., Mikkelsen, T., Astrup, P., Thykier-Nielsen, S., Jacobsen, L.H., Schou-Jensen, L., Hoe, S.C. \& Nielsen, S.P., 2008a. Estimation of health hazards resulting from a radiological terrorist attack in a city, Radiation Protection Dosimetry, Vol. 131, No. 3, pp. 297-307.

Andersson, K.G., Jones, A. \& Charnock, T., 2009. Estimation of doses in inhabited areas, Chapter 6 (pp. 147185 ) in K.G. Andersson (editor): Airborne radioactive contamination in inhabited areas, Book Series Radioactivity in the Environment vol. 15 (series editor: M.S. Baxter), Elsevier, ISBN 978-0-08-044989-0, ISSN 1569-4860.

ARGOS, 2018. PDC-ARGOS CBRN Crisis Management website. , www.pdc-argos.com/.

Bender, G.M. \& Terstriep, M.L., 1984. Effectiveness of street sweeping in urban runoff pollution control, Science of the Total Environment 33, 185-192.

BIOMOVS, 1991. Scenario 4. Multiple Model Testing using Chernobyl fallout data of I-131 and Cs-137 in forage, milk, beef and grain. H. Kohler, S.-R. Peterson \& F.O. Hoffmann (eds.). Technical Report 13, vols. I and II, Stockholm: National Institute of Radiation Protection. 
Blake, G.R., \& Hartge, K.H., 1986. Bulk density. p. 363-375. In A. Klute (ed.): Methods of soil analysis. Part 1. (2nd ed.). Agron. Monogr. 9. ASA and SSSA, Madison, WI.

Bossew, P. \& Kirchner, G., 2004. Modelling the vertical distribution of radionuclides in soil. Partl: the convection-dispersion equation revisited, J. Environ. Radioactivity 73, 127-150.

Brady, N.C. and Weil, R.R., 1996. The nature and properties of soils (11th ed.). Prentice Hall, New York.

Brewer, R., 1964. Fabric and mineral analysis of soils. Huntington, N.Y.: R.E. Krieger. ISBN 0882753142.

Brown, J., Ewers, L. \& Youngman, M., 2016. An experimental study on natural weathering of radionuclides

from urban surfaces for aerosols deposited in wet and dry conditions, Radioprotection 51'(HS2), S109-S112.

Bunzl, K., Schimmack, W., Zelles, L. \& Albers, B.P., 2000. Spatial variability of the vertical migration of fallout ${ }^{137} \mathrm{Cs}$ in the soil of a pasture, and consequences for long-term predictions, Radiat. Environ. Biophys. 39, pp. 197-205.

Byrne, M.A., 2009. Airborne contamination inside dwellings, Chapter 3 (pp. 55-75) in K.G. Andersson (editor): Airborne radioactive contamination in inhabited areas, Book Series Radioactivity in the Environment vol. 15 (series editor: M.S. Baxter), Elsevier, ISBN 978-0-08-044989-0, ISSN 1569-4860.

Chadwick, R.C. \& Chamberlain, A.C., 1970. Field loss of radionuclides from grass; Atmospheric Environment 4, pp. 51-56.

Charnock, T.W., 2018. Concise description of ERMIN 2.1. The European inhabited dose and decontamination model, Draft report, Centre for Radiation, Chemical and Environmental Hazards, Public Health England, Chilton, Didcot, Oxfordshire, OX11 ORQ, UK.

Charnock, T.W., Jones, J.A., Singer, L.N., Andersson, K.G., Roed, J., Thykier-Nielsen, S., Mikkelsen, T., Astrup, P., Kaiser, J.C., Müller, H., Pröhl, G., Raskob, W., Hoe, S.C., Jacobsen, L.H., Schou Jensen, L. \& Gering, F., 2009. Calculating the consequences of recovery, a European model for inhabited areas, Radioprotection vol. 44, No.5, pp. 407-412, ISSN 0033-8451.

Chesworth, W., 2008. Encyclopedia of soil science. Dordrecht, Netherlands: Springer. p. 694. ISBN 1402039948.

Cline, J.F., Wilson, D.O. \& Hubgate, F.P., 1965. Effect of physical and biological conditions on deposition and retention of 131 l on plants, Health Physics 11, pp. 713-717.

De Preter, 1990. Radiocaesium retention in the aquatic, terrestrial and urban environment: a quantitative and unifying analysis, Doktoraatsproefschrift Nr. 190 aan de Fakulteit der Landbouwwetenschappen, Katholieke Universiteit te Leuven, Belgium.

Eriksson, Å, Rosén, K. \& Haak, E., 1998. Retention of simulated fallout nuclides in agricultural crops, Swedish University of Agricultural Sciences, Uppsala (SE), Report SLU-REK-80, ISSN 0280-7963

Franzluebbers, A.J. , 2011.Stratification of soil porosity and organic matter, in Encyclopedia of Agrophysics, pp. 858-861, ISBN 978-90-481-3584-4, Springer Netherlands. 
Hansen, H.S. \& Hove, K., 1991. Radiocesium bioavailability - transfer of Chernobyl and tracer radiocesium to goat milk, Health Physics 60, 665-673.

Heinemann, K. \& Vogt, K.J., 1980. Measurements of the deposition of iodine onto vegetation and the biological half-life of iodine on vegetation, Health Physics 39, pp. 463-474.

Hinrichsen, Y. \& Andersson, K.G., 2018. Kerma factors for modern glass buildings in contaminated areas, paper submitted for publication in J. Radiological Protection.

Horticulture Diagnostic Laboratory, 2018. Normal Needle \& Foliage Shedding On Evergreens, Cornell University, Cooperative Extension of Suffolk University, NY

https://s3.amazonaws.com/assets.cce.cornell.edu/attachments/2182/Normal-Needle-And-Foliage-

Shedding-On-Evergreens.pdf?1408632735.

Hossain, M.F., Chen, W \& Zhang, Y, 2015. Bulk density of mineral and organic soils in the Canada's arctic and sub-arctic. Information Processing in Agriculture 2 (3-4) 183-190.

Howard, B.J., Fesenko, S., Balonov, M.I., Pröhl, G. \& Nakayama, S., 2017. A comparison of remediation after the Chernobyl and Fukushima Daiichi accidents, Rad. Prot. Dosimetry 173, 170-176.

IAEA, 1991. The International Chernobyl Project, Technical Report, Report by an Advisory Committee, IAEA, International Atomic Energy Agency, Vienna, ISBN 92-0-129191-4.

IAEA, 2009. Quantification of radionuclide transfer in terrestrial and freshwater environments for radiological assessments, IAEA-TECDOC-1616, ISBN 978-92-0-104509-6, IAEA, Vienna.

ICRP, 1997. Conversion coefficients for use in radiological protection against external radiation, Annals of the ICRP, ICRP Publication 74, Pergamon Press, Oxford/ New York/ Tokyo, ISSN 0146-6453.

Ivanov, Y., 2009. Migration of fuel particles of ChPP fallout and leached radionuclides in soils and soil-toplant system, In D.H. Oughton \& V. Kashparov (eds.): Radioactive particles in the environment, Proceedings of the NATO Advanced Research Workshop on Hot Particles Released from Different Nuclear Sources, Yalta, Ukraine, 7-10 May 2007, Springer, Dordrecht, The Netherlands, ISBN 978-90-481-2949-2.

Jacob, P., Meckbach, R. \& Müller, H.M., 1987. Reduction of external exposure from deposited Chernobyl activity by run-off, weathering, street cleaning and migration in the soil, Rad. Prot. Dosimetry 21, pp. 51-57.

Jones, A., Charnock, T., Singer, L., Roed, J., Andersson, K.G., Thykier-Nielsen, S., Mikkelsen, T., Astrup, P., Kaiser, J.C., Müller, H., Pröhl, G., Raskob, W., Hoe, S., Jacobsen, L.H., Schou-Jensen, L. \& Gering, F., 2007. Description of the modelling of transfer and dose calculations within ERMIN, Deliverable report D5C2R2 of the CEC-EURANOS project, EURANOS(CAT2)-TN(05)-04.

Karlberg, O., 1988. Weathering and migration of Chernobyl fallout in Sweden, Studsvik report NP 216 EA, Studsvik, Sweden.

Kashparov, V.A., Ahamdach, N., Zvarich, S.I., Yoschenko, V.I., Maloshtan, I.M. \& Dewiere, L., 2004. Kinetics of dissolution of Chernobyl fuel particles in soil in natural conditions, J. Environmental Radioactivity 72, 335-353. 
Kinase, S., Takahashi, T., Sato, S., Yamamoto, H. \& Saito, K., 2015. Prediction of ambient dose equivalent rates for the next 30 years after the accident, In Takahashi, T., Yamana, H., Tsukada, H., Sato, N., Nakatani, M.: Proceedings of the International Symposium on Radiological Issues for Fukushima's Revitalized Future, Paruse lizaka, Fukushima City, Japan, May 30-31, 2015, KUR Research Program for Scientific Basis of Nuclear Safety, Osaka, Japan, ISBN 9784 9906815-3-1.

Kirchmann, R., Fagniart, E. \& van Puymbroeck, S., 1966. Studies on foliar contamination by radiocaesium and radio-strontium, In: Radioecological concentration processes, Proceedings of an international symposium held in Stockholm, Sweden, 25-29 April 1966, Pergamon Press, London, pp. 475-483.

Kirchner, G. Strebl, F., Bossew, P., Ehlken, S. \& Geerzabek, M.H., 2009. Vertical migration of radionuclides in undisturbed grassland soils, J. Environ. Radioactivity 100, pp. 716-720.

Krieger, H.L. \& Burmann, F.J., 1969. Effective half-times of 85-Sr and 134-Cs for a contaminated pasture; Health Physics 17, pp. 811-824.

Linkov, I., Morel, B. \& Schell, W.R., 1997. "Remedial policies in radiologically-contaminated forests: environmental consequences and risk assessment", Risk Analysis 17, 67-75.

Madoz-Escande, C., Henner, P. \& Bonhomme, T., 2004. Foliar contamination of Phaseolus vulgaris with aerosols of $137 \mathrm{Cs}, 85 \mathrm{Sr}, 133 \mathrm{Ba}$ and $123 \mathrm{mTe}$ : influence of plant development stage upon contamination and rain, J. Environ. Radioactivity 73(1), pp. 49-71.

Madoz-Escande, C., Garcia-Sanchez, L., Bonhomme, T. \& Morello, M., 2005. Influence of rainfall characteristics on elimination of aerosols of caesium, strontium, barium and tellurium deposited on grassland, J. Environ. Radioactivity 84, pp. 1-20.

Madoz-Escande, C. \& Santucci, P., 2005. Weather-dependent change of caesium, strontium, barium and tellurium contamination deposited as aerosols on various cultures, J. Environ. Radioactivity 84, pp. 417-439.

Mamaev, L.A., Rybakov, K.A., Galkin, G.A., Ogulnik, P.G., Hrabrov, S.A., Karlin, N.E., Parhomenko, V.I., Davydov, Yu.P., Voronik, N.I., Shatilo, N.N., Dmitrieva, Z.S., Efremenkov, V.M., Kupriyanova, I.V. \& Kherovets, N.A., 1993. Development of technologies for decontamination of urban areas, techniques, motor transport, buildings, Progress report on the European Project ECP-4, Development of strategy for decontamination, Bochvar RIIM, Moscow, Russia / IREP of Ac. Sc, Belarus.

Mamikhin, S.V. \& Klyashtorin, A.L., 2000. Mathematical model of 137Cs dynamics in the deciduous forest, J. Environmental Radioactivity vol. 47, pp. 101-114.

Martin, W.E., 1964. Losses of Sr-90, Sr-89 and I-131 from fallout contaminated plants, Radiat. Bot. 4, pp. 275-284.

Mercer, T.T., 1967. On the role of particle size in the dissolution of lung burdens, Health Physics 13, 12111221.

Milbourn, G.M. \& Taylor, R., 1965. The contamination of grassland with radioactive strontium - I: Initial retention and loss; Radiat. Bot. 5, pp. 337-347. 
Mück, K., Roth, K., Gerzabek, M.H. \& Oberlander, H.-E., 1994. Effective half-lives of I- and Cs- isotopes in grassland shortly after fallout; J. Environ. Radioactivity 24(2), pp. 127-143.

Müller, H. \& Pröhl, G., 1993. ECOSYS-87: A dynamic model for assessing radiological consequences of nuclear accidents, Health Physics 64(3), pp. 232-252.

Nair, S. \& Darley, P.J.A., 1986. Preliminary assessment of individual doses in the environs of Berkeley, Gloucestershire, following the Chernobyl nuclear reactor accident, J. Soc. Radiol. Prot. 6(3), pp. 101-108.

Nygren, P., Hari, P., Raunemaa, T., Kulmala, M., Luokkanen, S., Holmberg, M. \& Nikinmaa, E., 1994. Behaviour of ${ }^{137} \mathrm{Cs}$ from Chernobyl fallout in a Scots pine canopy in southern Finland, Can. J. For. Res., 24, 1210-1215.

Owen, W.L., Sartor, J.D. and van Horn W.H., 1960. Performance characteristics of wet decontamination procedures, US Naval Radiological Defence Laboratory.

Périé, C., Ouimet, R.,2008. Organic carbon, organic matter and bulk density relationship in boreal forest soils, Soil Science 88, 315-325.

Ramzaev, V., Andersson, K.G., Barkovsky, A., Fogh, C.L., Mishine, A. \& Roed, J., 2006. Long-term stability of decontamination effect in recreational areas of the town Novozybkov, Bryansk Region, Russia, J. Environmental Radioactivity, vol. 85 (2-3), pp. 280-298.

RODOS, 2018. Realtime Online Decision Support System for nuclear emergency management. RODOS system home page, Karlsruhe Institute of Technology, Germany, https://resy5.iket.kit.edu/RODOS/.

Roed, 1987. Run-off from and weathering of roof material following the Chernobyl accident, Rad. Protection Dosimetry 21(1/3), 59-63.

Roed, J., 1988. The distribution on trees of dry deposited material from the Chernobyl accident, paper presented at the Joint CEC/OECD(NEA) Workshop on Recent Advances in Reactor Accident Consequence Assessment, Rome, Italy, 25-30 January, 1988.

Roed, J., 1990. Deposition and removal of radioactive substances in an urban area, Final report of the project NKA AKTU-245, NKA, ISBN 8773035149.

Roed, J. \& Jacob, P., 1990. Deposition on urban surfaces and subsequent weathering, Proceedings of a seminar on methods and codes for assessing the off-site consequences of nuclear accidents (vol. 1), Athens, Greece, 1990, EUR13013, pp. 335-356.

Rulik, P., Bucina, I. \& Malátová, I., 1989. Aerosol particle size distribution in dependence on the type of radionuclide after the Chernobyl accident and in the NPP effluents, Proceedings of the XVth Regional Congress of IRPA, Visby, Gotland, Sweden, pp. 102-107, ISBN 3-88585-668-9, TÜV Verlag Rheinland GmbH, Köln.

Sartor, J.D., Boyd, G.B., Agardy, F.J., 1974. Water pollution aspects of street surface contaminants, Journal WPCF, Water Pollution Control Federation, January 1974, pp. 456-467. 
Sartor, J.D. \& Gaboury, D.R., 1984. Street sweeping as a water pollution control measure: lessons learned over the past ten years, Science of the Total Environment 33, 171-183.

Schuller, P., Ellies, A. \& Kirchner, G., 1997. Vertical migration of fallout ${ }^{137} \mathrm{Cs}$ in agricultural soils from Southern Chile, The Science of the Total Environment 193, 197-205.

Sheppard, S., Long, J., Sanipelli, B,2009. Solid /liquid partition coefficients (Kd) for selected soils and sediments at Forsmark and Laxemar-Simpevarp, SKB Report R-09-27, Sweden, ISSN 14023091.

Terstriep, M.L., Bender, G.M. \& Noel, D.C., 1982. Final report, Nationwide urban runoff project, Champaign, Illinois: Evaluation of the effectiveness of municipal street sweeping in the control of urban storm runoff pollution, US Environmental Protection Agency.

Warming, L., 1982. Weathering and decontamination of radioactivity deposited on asphalt surfaces, Ris $\varnothing$ National Laboratory, Ris $\varnothing-\mathrm{M}-2273$.

Warming, L., 1984. Weathering and decontamination of radioactivity deposited on concrete surfaces, Ris $\varnothing$ National Laboratory, Ris $\varnothing-M-2473$.

Wilkins, B.T., 1987. The retention behaviour of radiocaesium on common building materials under natural outdoor conditions, Rad. Prot. Dosimetry vol. 21, no.1/3, pp. 69-73. 